\title{
Editorial: Targeting the Optimal Design and Operational Flexibility of Steam Cycles and Steam Networks
}

\author{
Emanuele Martelli $^{1 *}$ and Falah Alobaid ${ }^{2}$ \\ ${ }^{1}$ Department of Energy, Politecnico di Milano, Milan, Italy, ${ }^{2}$ Institute for Energy Systems and Technology, Technical University of \\ Darmstadt, Darmstadt, Germany
}

Keywords: steam cycles, combined cycles, cycle optimization, heat recovery, dynamic process simulation

Editorial on the Research Topic

Targeting the Optimal Design and Operational Flexibility of Steam Cycles and Steam Networks

\section{OPEN ACCESS}

Edited and reviewed by: Valerie Eveloy,

Khalifa University, United Arab

Emirates

*Correspondence:

Emanuele Martell emanuele.martelli@olimi.it

Specialty section:

This article was submitted to Process and Energy Systems Engineering,

a section of the journal Frontiers in Energy Research

Received: 31 August 2021 Accepted: 28 September 2021

Published: 22 October 2021

Citation:

Martelli $E$ and Alobaid $F$ (2021)

Editorial: Targeting the Optimal Design and Operational Flexibility of Steam

Cycles and Steam Networks.

Front. Energy Res. 9:768544.

doi: 10.3389/fenrg.2021.768544

\section{INTRODUCTION}

Steam cycles and steam networks are essential for a wide range of thermal power plants and industrial processes. Today steam cycles are used not only in fossil-fired power plants and nuclear power plants but also as heat recovery cycles in gas turbine combined cycles (GTCCs) (Gülen 2019), integrated gasification combined cycles (IGCCs) and polygeneration plants (e.g., coproducing electricity and hydrogen or synthesis fuels) (Elsido et al., 2019). Steam networks and combined heat and power cycles are typically used to optimize the heat integration of a wide range of industrial processes (Luo et al., 2016). Steam cycles are used also in renewable technologies such as concentrated solar power plants (Gonzalo et al., 2019) and large biomass-fired plants (Amec-Foster-Wheeler 2016), as well as wasteto-energy plants (Beiron et al., 2019). While steam cycle components are considered mature technologies, it is important to note that each application features a specific optimal thermodynamic design of the steam cycle (i.e., cycle configuration and steam pressures/ temperatures) as well as a tailored control strategy for off-design and ramping (Martelli et al.). While these criteria are well known for fired steam cycles and combined cycle power plants, those for novel energy systems (e.g., Integrated Solar Combined Cycles) are still an object of research and development efforts in both academia and industry [see, e.g., (Elsido et al. 2021), and (Temraz et al., 2021)]. Such efforts are spurred by the need of minimizing fuel consumption and the related environmental emissions. Furthermore, the increased penetration of renewable energy sources in the generation of electrical power recently raises technical and economic challenges for the operation of these plants. Existing thermal power plants have to be retrofitted with optimized components [e.g., warming and pre-warming systems for the steam turbine (Pehle et al., 2020)] and control systems (Casella et al., 2011) to improve their operational flexibility, such as ramping rates and shutdown/start-up times. Consequently, accurate dynamic simulation tools are being developed for developing novel equipment designs, control systems, and start-up procedures (Alobaid et al. 2017). 
This special collection intends to present an overview of the technology's state-of-the-art, novel applications, design criteria and methodologies, dynamic simulation tools, and optimization approaches.

\section{SPECIAL ISSUE CONTRIBUTIONS}

The paper (Stefanitsis et al.) proposes a 1-D dynamic process simulation model (validated with experimental data) for the combustion of solid fuels in a one $\mathrm{MW}_{\text {th }}$ circulating fluidized bed. It was found that the thermal energy storage system can improve the load flexibility of the circulating fluidized bed combustor, as the ramp-up and ramp-down times were shown to be significantly shorter.

The paper (Temraz et al.) investigated the dynamic instabilities of two-phase water/steam flows, an issue of great relevance for the accurate design and operation of thermal power plants, cryogenic processes and chemical plants. The dynamic instabilities of an evaporator pipe of a natural circulation vertical heat recovery steam generator were investigated experimentally.

The paper (Gülen) reviews the state-of-the-art in steam turbine technology and Rankine cycle in the context of thermal power plants, e.g., coal-fired power and combined cycle power. The steam cycle was analyzed based on a cycle analysis drawing upon the second law of thermodynamics and the concept of exergy. The status of technology development was discussed and how far it can still progress. Based on the comparison with supercritical $\mathrm{CO}_{2}$ cycles (a novel technology under development), the author concludes that steam cycles will continue to be the benchmark technology for most applications.

The paper (Mocholí Montañés et al.) proposes a method for optimizing simultaneously the thermodynamics and the heat exchanger geometries for compact bottoming cycles to be installed on offshore oil and gas platforms. By selecting ten different manufactural tubes, ten different designs were generated with optimum minimum weight for the bottom cycle. The selection of smaller outer tube diameters in the heat exchanger of the once-through steam generator is a critical factor for lightweight and compact steam cycle designs. The results show that more compact and lighter designs respond faster to changes in gas turbine operation and can reduce controlling difficulties and stabilize bottoming cycles for power generation.

\section{REFERENCES}

Alobaid, F., Mertens, N., Starkloff, R., Lanz, T., Heinze, C., and Epple, B. (2017). Progress in dynamic simulation of thermal power plants. Progress in energy and combustion science 59, 79-162. doi:10.1016/j.pecs.2016.11.001

Amec-Foster-Wheeler (2016). Amec Foster Wheeler Wins UK Biomass Fired CFB Boiler Contract. Pump Industry Analyst 9 (3), 1. doi:10.1016/s1359-6128(16) 30261-0

Beiron, J., Montañés, R. M., Normann, F., and Johnsson, F. (2019). Dynamic Modeling for Assessment of Steam Cycle Operation in Waste-Fired Combined Heat and Power Plants. Energ. Convers. Management 198, 111926. doi:10.1016/ j.enconman.2019.111926
The review paper (Martelli et al.) provides a comprehensive review of simulation and optimization approaches related to steam cycles: 1) the mathematical background relevant to power plant simulation and optimization problems (both steady-state and dynamic) and codes, 2) approaches, criteria and software used to design and optimize steam cycles, 3) methodologies for the design optimization of novel steam cycles and complex steam networks, 4) studies on the dynamic simulation of steam cycles. The final section of this review highlights current research trends and points out important research gaps to be addressed.

\section{CONCLUSION}

The editors of this special collection are pleased to bring a clear review of the state-of-the-art as well as recent advancements in steam cycle power plants to the scientific community. The contributions also pointed out important research gaps to be addressed, namely, 1) investigating experimentally the effect of evaporator pipe orientation and the pressure on two-phase flow dynamic instabilities, 2) developing methodologies and software for the combined optimization of cycle design, off-design operation, and plant dynamics (start-up/shut-down, ramping) considering thermo-mechanical stresses acting on thick-wall components, 3) performing dynamic analyzes of integrated steam cycles such as those used in integrated gasification combined cycles.

\section{AUTHOR CONTRIBUTIONS}

All authors listed have made a substantial, direct, and intellectual contribution to the work and approved it for publication.

\section{ACKNOWLEDGMENTS}

The editors would like to thank the senior journal specialist Joshua Stocco and the interim journal manager Josh Kellie for the technical support and organizational management of this Special Collection. Furthermore, many thanks go to all the reviewers for reviewing the above-referenced manuscripts.

Casella, F., Farina, M., Righetti, F., Faille, D., Tica, A., Gueguen, H., et al. (2011). An Optimization Procedure of the Start-Up of Combined Cycle Power Plants. IFAC Proc. 44 (1), 7043-7048. doi:10.3182/20110828-6-it-1002.00604

Elsido, C., Martelli, E., and Kreutz, T. (2019). Heat Integration and Heat Recovery Steam Cycle Optimization for a Low-Carbon lignite/biomass-to-jet Fuel Demonstration Project. Appl. Energ. 239, 1322-1342. doi:10.1016/ j.apenergy.2019.01.221

Elsido, C., Martelli, E., and Grossmann, I. E. (2021). Multiperiod optimization of heat exchanger networks with integrated thermodynamic cycles and thermal storages. Computers \& Chemical Engineering 149, 107293. doi:10.1016/ j.compchemeng.2021.107293

Gülen, S. C. (2019). Gas Turbines for Electric Power Generation. Cambridge University Press. 
Luo, X., Huang, X., El-Halwagi, M. M., Ponce-Ortega, J. M., and Chen, Y. (2016). Simultaneous Synthesis of Utility System and Heat Exchanger Network Incorporating Steam Condensate and Boiler Feedwater. Energy 113, 875-893. doi:10.1016/j.energy.2016.07.109

Pehle, L., Łuczyński, P., Jeon, T., Wirsum, M., Mohr, W. F., and Helbig, K. (2020). "Comparison of Steam Turbine Pre-warming and Warm-Keeping Strategies Using Hot Air for Fast Turbine Start-Up," in Turbo Expo: Power for Land, Sea, and Air (American Society of Mechanical Engineers (ASME)). doi:10.1115/ gt2020-14281

Peinado Gonzalo, A., García Márquez, A.F. P., and Márquez, F. P. G. (2019). A review of the application performances of concentrated solar power systems. Applied Energy 255, 113893. doi:10.1016/ j.apenergy.2019.113893

Temraz, A., Alobaid, F., Link, J., Elweteedy, A., and Epple, B. (2021). Development and Validation of a Dynamic Simulation Model for an Integrated Solar Combined Cycle Power Plant. Energies 14 (11), 3304. doi:10.3390/en14113304
Conflict of Interest: The authors declare that the research was conducted in the absence of any commercial or financial relationships that could be construed as a potential conflict of interest.

Publisher's Note: All claims expressed in this article are solely those of the authors and do not necessarily represent those of their affiliated organizations, or those of the publisher, the editors and the reviewers. Any product that may be evaluated in this article, or claim that may be made by its manufacturer, is not guaranteed or endorsed by the publisher.

Copyright (c) 2021 Martelli and Alobaid. This is an open-access article distributed under the terms of the Creative Commons Attribution License (CC BY). The use, distribution or reproduction in other forums is permitted, provided the original author(s) and the copyright owner(s) are credited and that the original publication in this journal is cited, in accordance with accepted academic practice. No use, distribution or reproduction is permitted which does not comply with these terms. 